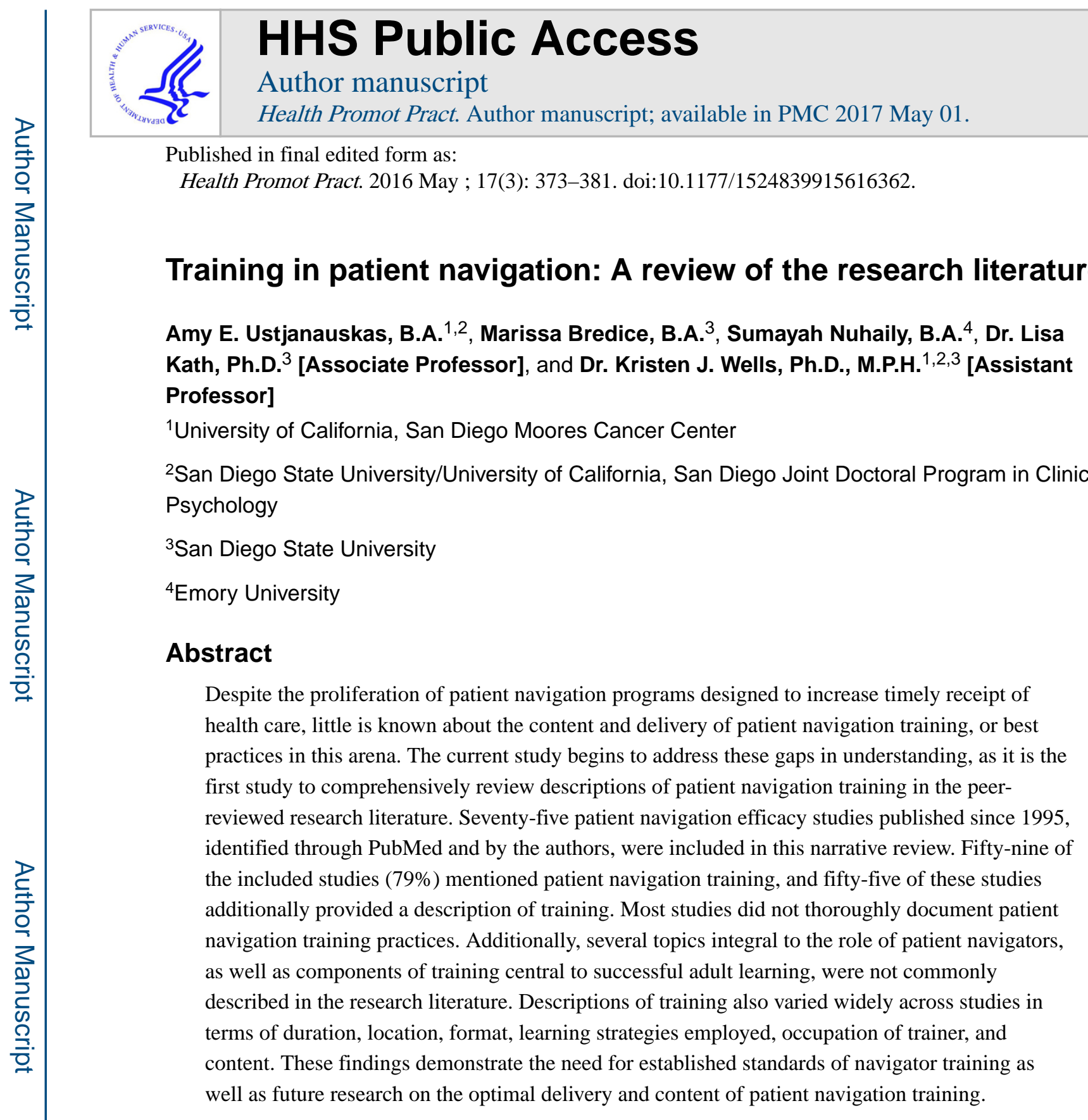

Keywords

patient navigation; training; review

\title{
Introduction
}

The term patient navigation (PN) was first coined by Dr. Harold Freeman and describes an intervention which aims to help patients overcome barriers to completing a health care goal (Dohan \& Schrag, 2005; Freeman, Muth, \& Kerner, 1995; Wells et al., 2008). PN programs

Address Correspondence to: Kristen J. Wells, Ph.D., M.P.H., Department of Psychology, San Diego State University, 6363 Alvarado Court, Suite 103, San Diego, CA 92120-4913, Office: 619-594-1919, Fax: 619-594-6780, kwells@ mail.sdsu.edu.

austjanauskas@gmail.com,marissa.bredice@gmail.com, sumayah.nuhaily@emory.edu, 1kath@mail.sdsu.edu 
are being implemented throughout the United States as research continues to evaluate their effectiveness (Dohan \& Schrag, 2005; Wells et al., 2008). PN is associated with improvements in screening and diagnostic services for certain diseases, such as breast, colorectal, and prostate cancer, but has not been well-investigated for other diseases and cancers (Paskett, Harrop, \& Wells, 2011; Wells et al., 2008).

There are currently three competing viewpoints regarding the best model of PN based on navigator training and background. These models include: 1) a lay navigator that is culturally-competent and/or appropriately trained; 2 ) a professional navigator (either a nurse or social worker); or 3) a multidisciplinary team that includes both lay and professional navigators (Braun et al., 2012; Freeman, 2012; Hopkins \& Mumber, 2009; National Accreditation Program for Breast Centers, 2014; Oncology Nursing Society, Association of Oncology Social Work, \& National Association of Social Workers, 2010). In a multidisciplinary team, it is suggested that professional navigators perform more technical tasks or supervise lay navigators (Freeman, 2012; Oncology Nursing Society et al., 2010).

There has been a movement to include $\mathrm{PN}$ in health care legislation and accreditation standards, and professional organizations have provided guidelines regarding how navigation should ideally be implemented (American College of Surgeons Commision on Cancer, 2012; National Accreditation Program for Breast Centers, 2014; Oncology Nursing Society et al., 2010; "Patient Navigator Outreach and Chronic Disease Prevention Act," 2005; "Patient Protection and Affordable Care Act," 2010). Nearly all legislation, standards, and guidelines have indicated that appropriate training of patient navigators is critical.

The Patient Navigator Outreach and Chronic Disease Prevention Act (2005) defined patient navigators as individuals who have completed a training program approved by the Secretary of State and specified that grant recipients must use funds to train and employ patient navigators. More recently, PN was included in the Patient Protection and Affordable Care Act (2010), which describes that grants provided to institutions for PN must ensure that "navigators are recruited, assigned, trained, or employed using grant funds."

There are two accreditation standards that include PN as a requirement. The American College of Surgeons Commission on Cancer (2012) released standards requiring accredited institutions to establish a PN process by 2015. Additionally, the National Accreditation Program for Breast Centers' (2014) standards require that a "PN process is in place to guide a patient with a breast abnormality through provided and referred services." The accreditation standards indicate that PN should be provided by a professional navigator who is trained to provide "individualized assistance to cancer patients, families, and caregivers at risk." The standards do allow non-professional navigators to provide services to patients as long as they receive training from a "recognized professional organization."

In addition, three professional organizations, the Oncology Nursing Society, the Association of Oncology Social Work, and the National Association of Social Workers (2010), released a joint position statement on the role of oncology nurses and social workers in PN. The statement stresses the importance of educational preparation and professional certification for oncological nurse and social worker patient navigators. It also describes that navigation 
services may be implemented by a trained lay navigator, but that lay navigators should be supervised by professional navigators.

While accreditation standards, health care legislation, and multiple organizations all emphasize the importance of trained patient navigators, no nationally-established certifications or standards for PN training exist, and little is known about the optimal delivery and content of training (DeGroff, Coa, Morrissey, Rohan, \& Slotman, 2014; Shelton et al., 2011). Two established PN training programs exist in the United States: the Harold P. Freeman Patient Navigation Institute and the Colorado Patient Navigator Training Program, which provide training to navigators regardless of program affiliation. Additionally, several PN programs, including the Patient Navigation Research Program (PNRP) have developed their own program-specific training curricula (Calhoun et al., 2010; DeGroff et al., 2014). Little research, however, has been conducted in the area of PN training.

Nine published articles focus exclusively on PN training programs (Braun, Allison, \& Tsark, 2008; Bryant, Williamson, Cartmell, \& Jefferson, 2011; Calhoun et al., 2010; Fernandes, Riklon, Langidrik, Williams, \& Kabua, 2014; Klimmek et al., 2012; Ostroff et al., 2011; Schapira \& Schutt, 2011; Shelton et al., 2011; Sly et al., 2012). All nine studies described the content of their training programs and additionally evaluated their training programs using metrics such as knowledge, self-efficacy, satisfaction, and competency engaging in specific navigator skills. Five studies also described the development of training curricula (Braun, Allison, \& Tsark, 2008; Calhoun et al., 2010; Klimmek et al., 2012; Ostroff et al., 2011; Schapira \& Schutt, 2011). One source of information regarding PN training is research studies that have been published in peer-reviewed literature. To date, two reviews of the PN literature, that were not specific to training, included descriptions of the content of PN training programs described in the articles they reviewed (DeGroff et al., 2014; Ghebre et al., 2014). However, both of these reviews were very limited in that each only described training delivered in five or fewer studies (DeGroff et al., 2014; Ghebre et al., 2014). Thus, the objective of this comprehensive narrative review of the PN literature is to evaluate the provision of PN training documented in published research articles. Compiling this information about patient navigation training will enable the field of health promotion to identify strengths and gaps in patient navigation training, as well as facilitate the process of linking the research conducted on patient navigation with the implementation of patient navigation.

\section{Extensive literature review}

\section{Methods}

A PubMed search was conducted in May 2014 to identify PN efficacy studies published since 1995. Search terms used to identify articles included: client navigat*, patient navigat*, clinical navigat*, system navigat*, and professional navigat*. Publications meeting four inclusion criteria were included in the review: 1) written in English; 2) conducted in the United States; 3) compared the efficacy of PN to another condition (e.g., usual care, written materials, or control group) with respect to impact on a specific health outcome; and 4) presented analyses on adherence, quality of care, prognosis, or survival outcomes related to disease control, treatment, or survivorship. PN was broadly defined as "an intervention 
which aims to help patients overcome barriers to completing a health care goal" (Dohan \& Schrag, 2005; Freeman et al., 1995; Wells et al., 2008). Previous systematic or narrative reviews, as well as studies where the sole outcome was a psychosocial construct were excluded. Additionally, articles identified by the study authors from previous reviews of the literature that met inclusion criteria were included in the review.

The search yielded 441 abstracts. One researcher conducted an initial review of abstracts to determine if articles met inclusion criteria; the same researcher conducted an additional review of full publications to verify that inclusion criteria were met. Sixty-three studies were excluded because they were not conducted in the United States and/or were not written in English; an additional 290 studies were excluded because they did not compare the efficacy of PN to another condition with respect to impact on a specific health outcome; and 13 reviews were excluded. In total, 75 articles (see Appendix 1) met inclusion criteria and were included in this review. Two researchers divided the 75 publications meeting inclusion criteria in half, and abstracted content describing PN training. One of these researchers conducted a second review of the publications, to check the accuracy of the abstraction.

A systematic method of review was conducted using a formalized data abstraction template (see Appendix 2). The data abstraction template was informed by three main sources: 1) knowledge of existing PN programs; 2) learning theory; and 3) general principles of employee training and development, as well as industrial-organizational psychology. Knowledge of existing PN programs provided the basis for several codes included in the data abstraction template. Codes were also created to capture key tenets of adult learning theory and learning theory generally. Adult learning theory specifies that adults are autonomous and self-directed learners that should be involved in the planning of learning experiences, and provided with support during learning experiences (Calhoun et al., 2010; Merriam, Caffarella, \& Baumgartner, 2007; Thompson, 2009). As such, codes were created to capture supervision and support of navigators, as well as navigator involvement in developing training content. General learning theory specifies that there are various styles of learning, and that individuals vary with respect to how they learn (Calhoun et al., 2010). Accordingly, a variety of common learning strategies and training formats were included in the data abstraction template. Further, general principles of employee training and development as well as industrial-organizational psychology were used not only to inform codes, but also to inform meaningful ways of categorizing training content (Noe, 2005). Three of the study authors developed the data abstraction template using an iterative process; that is, the template was pilot-tested and revised several times before being applied to abstract data from publications included in this study. One author primarily coded the articles, but consulted with the other authors until a consensus was met regarding how to address any difficult-to-code content.

Studies were initially coded with respect to whether or not PN training was mentioned or described. Studies describing training were further coded for six key domains of navigator training: duration, location, format, content, occupation of trainer, and learning strategy employed. Training duration or frequency included whether the training was massed (i.e., consolidated into a single time frame measured in hours or days) or distributed (i.e., spaced out over time). Specific learning strategies employed in training included whether the 
learning strategy was passive, which includes activities such as listening, reading, watching, or observing; or active, which includes the process of engaging in an activity. Additional content not falling into the six main domains of navigator training was also coded, including supervision, navigator networking, navigator involvement in developing training content, whether or not navigators were paid, and use of manualized navigation interventions.

Researchers noted the number of studies included in the review that mentioned training, and further described training. Additionally, researchers identified and compared core features of training across studies. For such comparisons, researchers present the number of studies describing a particular characteristic of training as a percentage of studies mentioning training.

Additionally, preliminary analyses were conducted comparing PN training by model of navigation (lay navigator, which included community health workers engaging in PN; professional navigator; and multidisciplinary team of lay and professional navigators).

\section{Results}

Seventy-five PN studies were included in this review. Studies varied with respect to model of navigation, as well as disease type and stage of disease continuum targeted by navigation. Table 1 provides characteristics of included studies.

Fifty-nine of the seventy-five studies included in this analysis (79\%) mentioned PN training. Of the 59 studies that mentioned training, 55 (93\%) additionally provided a description of PN training. Table 2 shows the training domains described in studies mentioning training. Thirty-five studies described three or fewer PN training domains. Only 13 studies described 4 training domains, and only 11 studies described 5 training domains. No studies described all six domains of PN training.

Training duration-Of the studies mentioning training, 31 (53\%) described the frequency or duration of PN training. Training duration varied widely, ranging from 12 hours to more than 12 months. Training duration and frequency differed across studies with respect to whether training was distributed over time or massed. Six studies provided massed training only, eleven studies provided distributed training only, and thirteen studies employed a combination of the two. Of the studies providing distributed training, weekly or monthly training schedules were most common ( $n=6$ for each), followed by annual trainings $(n=5)$, bi-monthly trainings $(n=2)$, and bi-yearly trainings $(n=1)$.

Training location and format-Training location was described in $16(27 \%)$ of the studies mentioning training. Navigators in six studies participated in local training only; navigators in one study participated in national training only, and navigators in eight studies participated in a combination of local and national training.

Training format varied widely across studies and was described in 27 (46\%) of the studies mentioning training. Six studies conducted training via classes. Trainees attended staff meetings in five studies, training programs in five studies, and training conferences in four studies. Telephone-based training and webinars were each utilized in two studies; and 
workshops, symposia, and educational updates were each described in one study. Several studies described non-specific training formats $(n=13)$, such as training sessions. Most studies only utilized one training format $(n=19)$, whereas four studies utilized two training formats, and four studies utilized a combination of between three and five training formats.

Occupation of trainer-Thirty of the studies mentioning training (51\%) also described who conducted the training. Most commonly, a research investigator implemented PN training $(n=20)$. In 12 studies, a medical worker conducted the training. Other individuals that conducted training included social workers, clinical psychologists, community health directors, and human resources staff. Training was self-administered in one study.

Learning strategy-Sixteen of the studies mentioning training (27\%) described specific learning strategies employed to train navigators. Six studies described solely using passive learning strategies, four studies described only using active learning strategies, and six studies utilized both types of learning strategies. Passive learning strategies employed to train navigators included the use of written materials such as manuals or handouts $(n=8)$, observations $(n=3)$, lectures $(n=2)$, and videos $(n=1)$. Active learning strategies described in the PN training literature included role-play, experiential exercises, and interactive games $(n=8)$; on-the-job training $(n=3)$; and group discussions $(n=1)$. Nine studies utilized a single learning strategy to train navigators, whereas five studies utilized two learning strategies, and two studies utilized three or more learning strategies.

Training content-Training content was described in 47 studies (80\% of the studies mentioning training). Table 3 provides the number of studies describing training content by type. Training content included topics related to patient care $(n=33)$; developing navigator skills $(n=28)$; and cancer and health education $(n=23)$. Other topics addressed included training in navigation generally $(n=16)$ and training in research or intervention protocols $(n$ $=9)$.

Of those studies with training focused on topics related to patient care, training in general coordination of care was the most common $(n=26)$. Training on general coordination of care included content on appointment scheduling; case management; coordinating medical testing, procedures, and follow-up; and navigating the health system. Fourteen studies provided content on overcoming barriers to care in their PN training curricula. Specifically, four studies included content on structural and logistical barriers; three studies described insurance barriers; two studies covered financial barriers; one study detailed transportation barriers; and one study addressed safety concerns. Ten studies included content in their training curricula on addressing psychosocial needs, including addressing cancer-related fears, providing support, and managing anger. Patient-provider issues, including patientprovider communication, medical mistrust, and medical interpretation, were included as training content in four studies. Three studies covered adherence strategies in their training curricula.

Studies including training content on developing navigator skills, most commonly focused on the delivery of theory-based techniques $(n=17)$, including motivational interviewing, reflective-listening, stages of change, and developing trusting relationships. Other navigator 
skills emphasized in training curricula included cultural competency $(n=14)$; assessment techniques $(n=8)$; communication skills $(n=7)$, including training in public speaking, telephone calls, interviews, and information presentation; confidentiality and privacy practices training $(n=4)$; maintaining professional boundaries $(n=3)$, including training in self-disclosure; and computer skills $(n=1)$.

Other training characteristics-Thirty-three studies mentioned that supervision was provided to patient navigators. Only one study described navigators being involved in the development of training content. Ten studies described that patient navigators were paid, and seven studies described that navigators utilized manualized interventions, such as scripts or intervention protocols. Additionally, navigator networking was described in two studies.

Training by navigation model-Preliminary analyses were conducted investigating PN training by model of navigation. Of the 75 articles included in this study, 11 studies described navigation implemented by a multidisciplinary team (i.e., by lay and professional navigators), of which all mentioned navigator training; 23 studies described navigation implemented by lay navigators only, of which $21(91 \%)$ mentioned navigator training; and 12 studies described navigation implemented by professional navigators only, of which 6 (50\%) mentioned navigator training. In 29 additional studies, type of navigation model was unclassifiable (i.e., the level of detail provided in the article did not lend to clear classification of navigators as lay only, professional only, or multidisciplinary team). Of these studies, 21 (72\%) mentioned navigator training.

With respect to training duration, lay navigators most commonly received a combination of massed and distributed training ( $38 \%$ of studies mentioning training). Training duration for professional navigators was equally described as distributed only, or a combination of massed and distributed (17\% of studies mentioning training, respectively), and training duration for multidisciplinary teams was equally described as distributed only, massed only, or a combination of massed and distributed (18\% of studies mentioning training, respectively). Location of lay navigator training was equally described as local only, or a combination of local and national (14\% of studies mentioning training, respectively), while location of training for multidisciplinary teams was most commonly described as a combination of local and national ( $27 \%$ of studies mentioning training). No studies described location of training for professional navigators. With regards to training format, lay navigator training varied (each study described using between one and five training formats, including classes, training programs, staff meetings, and conferences, among other formats). Training format for multidisciplinary teams and professional navigators was described in few studies and mainly included non-specific training formats (e.g., training sessions). Occupation of trainer did not vary by navigation model. Multidisciplinary teams as well as lay and professional navigators most commonly received training from research investigators or medical workers. Supervision, however, was most commonly provided to lay navigators as compared to multidisciplinary teams and professional navigators ( $71 \%$ versus $45 \%$ and $17 \%$ of studies mentioning training, respectively). One-fifth of studies mentioning the training of lay navigators used passive learning strategies (manuals or handouts), while an additional one-fifth of studies utilized active, or a combination of active and passive 
learning strategies. Multidisciplinary teams and professional navigators were trained via a combination of active and passive learning strategies. With regards to training content, multidisciplinary teams most commonly received training on topics related to patient care, followed by cancer and health education, and developing navigator skills $(45 \%, 36 \%$, and $27 \%$ of studies mentioning training, respectively); lay navigators most commonly received training on topics related to patient care, followed by training on developing navigator skills and cancer and health education $(52 \%, 43 \%$, and $43 \%$ of studies mentioning training, respectively); and professional navigators most commonly received training in topics related to patient care or developing navigator skills, followed by cancer and health education (50\%, $50 \%$, and $33 \%$ of studies mentioning training, respectively).

\section{Discussion}

Despite the call for trained patient navigators from professional organizations, health care legislation, and accreditation standards (American College of Surgeons Commision on Cancer, 2012; National Accreditation Program for Breast Centers, 2014; Oncology Nursing Society et al., 2010; "Patient Navigator Outreach and Chronic Disease Prevention Act," 2005; "Patient Protection and Affordable Care Act," 2010), little is known about the content and delivery of PN training, or best practices in this arena (Shelton et al., 2011). The present study begins to address these gaps in understanding, as it is the first study to comprehensively review descriptions of PN training in the peer-reviewed research literature.

The present study revealed that PN training is not thoroughly documented in research, even though reporting guidelines for randomized trials of behavioral medicine interventions indicate this information is critical (Davidson et al., 2003). While three-quarters of studies included in this analysis mentioned PN training, few comprehensively documented training protocols. No studies described all six domains of training assessed in this study: duration, location, format, content, occupation of trainer, and learning strategy employed. In fact, the majority of studies mentioning training described three or fewer of these training domains. In particular, approximately one-half or fewer studies described training duration, format, location; learning strategies; and occupation of trainer, respectively.

This research also demonstrated that PN training varies widely across studies. Duration of training ranged from 12 hours to more than 12 months, and differed with respect to distribution schedule (massed vs. distributed). Training also differed with respect to where it was conducted (nationally vs. locally) and who conducted the training. Training format and learning strategies employed also varied widely across studies. For instance, 12 different training formats were described, ranging from in-person, to telephone or computer-based formats. The most frequently described areas of training included techniques in care coordination; cancer and health education; theory-based techniques; cultural competency; and overcoming barriers to health care. However, these content areas were still not described in a large number of studies. Fewer than one-third of articles described training that provided navigators with skills in evidence-based behavior change approaches. Further, less than onequarter of studies described training on skills related to overcoming barriers to care. This is concerning as it is well agreed upon in the field that one of the main roles of the patient navigator is to assist individuals in overcoming barriers to care (Clark, Parker, Battaglia, \& 
Freund, 2014). Other gaps in training content elucidated through this review include training in confidentiality and privacy practices, and training in maintaining professional boundaries, which were each described in fewer than four studies.

One likely factor contributing to these important topics not being commonly covered in training is the fact that there exists uncertainty regarding the core competencies that a navigator should possess (Byers, 2012). The Patient Protection and Affordable Care Act (2010) illustrates this point as it states that recipients of PN grants must employ navigators that meet minimum core competencies, but that these core competencies are defined by each grant recipient, as opposed to being defined by established standards. In fact, no established competency standards applicable to all models of PN exist (Byers, 2012). The Oncology Nursing Society (2013) recently issued a list of core competencies for nurse navigators (i.e., professional navigators), including professionalism, provision of education, coordination of care, and communication; however, it is unclear if these competencies are applicable to other models of navigation, such as lay navigators, which may require different skills. The wide variation of navigator training across studies, coupled with the fact that several topics integral to the role of patient navigators are not commonly described in navigator training curricula, demonstrates the need for established competency standards for navigators as well as standards of navigator training to provide navigators with the knowledge, skills, and competencies fundamental to their success.

This study also revealed components of training integral to adult learning that were not commonly described in the literature. For instance, learning strategies were documented in very few studies. Of those studies describing learning strategies, the majority only utilized a single learning strategy. Additionally, only six studies employed a combination of passive and active learning strategies to train navigators. Along these lines, most studies only utilized one format to train navigators. Research on learning shows that individuals vary with respect to which learning style is the most effective (Calhoun et al., 2010); therefore, a combination of approaches may be most effective in training navigators of diverse backgrounds. Additionally, adult learning theory specifies that adult learners need to be involved in the planning, implementation, and evaluation of learning experiences (Thompson, 2009). Only one study described navigator involvement in the development of training content; therefore, this may be an area in which current training can improve. Adult learning theory also specifies that adults should be supported in their learning experiences (Merriam et al., 2007). Notably, while a description of supervision of treatment providers is critical to include in research studies of behavioral medicine interventions (Davidson et al., 2003), this review found that supervision provided to navigators was not described in all studies. Additionally, few studies described training via distance learning (e.g., by telephone or webinar) which may be an additional modality for providing continuing education or training to navigators. Research is needed to evaluate which learning techniques, strategies, and formats are most effective for patient navigators of diverse backgrounds.

The authors also conducted preliminary analyses comparing PN training by model of navigation. Studies describing navigation conducted by lay navigators or multidisciplinary teams more commonly described training as compared to those studies with navigation implemented by professional navigators. While the authors present differences and 
similarities in training across the three models of navigation, few notable differences emerged. One noteworthy trend, however, is that lay navigators most commonly received supervision. Findings from these preliminary analyses should be taken with caution, as the sample sizes for these analyses were very small. Future research comparing training by model of navigation should be conducted. Additionally, while this review included patient navigation studies as applied to any disease, most studies focused on cancer, and it did not compare navigator training by disease type due to limited sample sizes. Future research would benefit from investigating best practices in navigator training as applied to cancer, as well as other diseases. In addition, future research should identify how variation in training affects health outcomes and apply these findings to the implementation of patient navigation programs.

Although this narrative review is the first to comprehensively evaluate PN training documented in research literature, it is not without limitations. The study is based on a critical review of 75 PN efficacy studies identified through PubMed and by the research team. All studies were written in English and published in the United States since 1995, comparing the efficacy of PN to another condition. Studies on PN published in other countries, languages, and databases, or with different research designs, were not included in this review, and may provide additional information on PN training. Notably, elimination of papers discussing PN training without related program outcomes may limit the full understanding of current training programs and successful educational strategies. Future research should include a systematic review evaluating a broader range of published and unpublished research literature documenting patient navigator training. As the best practices of patient navigation training are identified in research, these practices should be implemented in training patient navigators to improve health outcomes.

\section{Conclusions}

Overall, this narrative review of the PN literature revealed that training of patient navigators is not thoroughly documented, as recommended in guidelines for behavioral medicine intervention research (Davidson et al., 2003). Among those studies describing PN training, this review also found that training curricula vary widely in terms of duration, location, format, learning strategies employed, occupation of trainer, and content. This review also exposed several skills integral to the role of patient navigators as well as components of training central to successful adult learning that were not commonly documented in the literature. These findings, combined with the demand for appropriately trained navigators expressed by professional organizations, health care legislation, and accreditation standards, demonstrate the need for PN competency standards and standards of navigator training, as well as research on the optimal delivery and content of PN training.

\section{Acknowledgements}

Research reported in this publication was supported by the National Cancer Institute of the National Institutes of Health under the following awards: U54 CA132384, U54 CA132379, and R21CA161077. The content is solely the responsibility of the authors and does not necessarily represent the official views of the National Institutes of Health. 


\section{Appendix 1: Seventy-Five Studies Included in Review}

\section{References}

1. Basu M, Linebarger J, Gabram SGA, Patterson SG, Amin M, Ward KC. The effect of nurse navigation on timeliness of breast cancer care at an academic comprehensive cancer center. Cancer. 2013; 119(14):2524-2531. DOI: 10.1002/cncr.28024 [PubMed: 23585059]

2. Battaglia TA, Bak SM, Heeren T, Chen CA, Kalish R, Tringale S, Freund KM. Boston patient navigation research program: The impact of navigation on time to diagnostic resolution after abnormal cancer screening. Cancer Epidemiology Biomarkers \& Prevention. 2012; 21(10):16451654. DOI: 10.1158/1055-9965.epi-12-0532

3. Battaglia TA, Roloff K, Posner MA, Freund KM. Improving follow-up to abnormal breast cancer screening in an urban population - A patient navigation intervention. Cancer. 2007; 109(2):359-367. DOI: 10.1002/cncr.22354 [PubMed: 17123275]

4. Bensink ME, Ramsey SD, Battaglia T, Fiscella K, Hurd TC, McKoy JM, Patient Nav Res P. Costs and outcomes evaluation of patient navigation after abnormal cancer screening evidence from the Patient Navigation Research Program. Cancer. 2014; 120(4):570-578. DOI: 10.1002/cncr.28438 [PubMed: 24166217]

5. Bradford JB, Coleman S, Cunningham W. HIV system navigation: An emerging model to improve HIV care access. Aids Patient Care and STDs. 2007; 21:S49-S58. DOI: 10.1089/apc.2007.9987 [PubMed: 17563290]

6. Braschi CD, Sly JR, Singh S, Villagra C, Jandorf L. Increasing colonoscopy screening for Latino Americans through a patient navigation model: A randomized clinical trial. Journal of immigrant and minority health / Center for Minority Public Health. 2014; 16(5):934-940. DOI: 10.1007/ s10903-013-9848-y [PubMed: 23736964]

7. Burhansstipanov L, Dignan MB, Schumacher A, Krebs LU, Alfonsi G, Apodaca CC. Breast screening navigator programs within three settings that assist underserved women. Journal of Cancer Education. 2010; 25(2):247-252. DOI: 10.1007/s13187-010-0071-4 [PubMed: 20300914]

8. Carrasquillo O, Patberg E, Alonzo Y, Li H, Kenya S. Rationale and design of the Miami Healthy Heart Initiative: A randomized controlled study of a community health worker intervention among Latino patients with poorly controlled diabetes. International journal of general medicine. 2014; 7:115-126. DOI: 10.2147/ijgm.s56250 [PubMed: 24600243]

9. Chen F, Mercado C, Yermilov I, Puig M, Ko CY, Kahn KL, Gibbons MM. Improving breast cancer quality of care with the use of patient navigators. American Surgeon. 2010; 76(10):1043-1046. [PubMed: 21105605]

10. Chen MS, Fang DM, Stewart SL, Ly MY, Lee S, Dang JHT, Bastani R. Increasing Hepatitis B screening for Hmong adults: Results from a randomized controlled community-based study. Cancer Epidemiology Biomarkers \& Prevention. 2013; 22(5):782-791. DOI: 10.1158/1055-9965.epi-12-1399

11. Christie J, Itzkowitz S, Lihau-Nkanza I, Castillo A, Redd W, Jandorf L. A randomized controlled trial using patient navigation to increase colonoscopy screening among low-income minorities. Journal of the National Medical Association. 2008; 100(3):278-284. [PubMed: 18390020]

12. Clark CR, Baril N, Kunicki M, Johnson N, Soukup J, Ferguson K, Bigby J. Addressing social determinants of health to improve access to early breast cancer detection: Results of the Boston Reach 2010 Breast and Cervical Cancer Coalition Women's Health Demonstration Project. Journal of Womens Health. 2009; 18(5):677-690. DOI: 10.1089/jwh.2008.0972

13. Dignan MB, Burhansstipanov L, Hariton J, Harjo L, Rattler T, Lee R, Mason M. A comparison of two Native American navigator formats: Face-to-face and telephone. Cancer control: Journal of the Moffitt Cancer Center. 2005; 12(Suppl 2):28-33. [PubMed: 16327748]

14. Donaldson EA, Holtgrave DR, Duffin RA, Feltner F, Funderburk W, Freeman HP. Patient navigation for breast and colorectal cancer in 3 community hospital settings. Cancer. 2012; 118(19):4851-4859. DOI: 10.1002/cncr.27487 [PubMed: 22392629]

15. Dudley DJ, Drake J, Quinlan J, Holden A, Saegert P, Karnad A, Ramirez A. Beneficial effects of a combined navigator/promotora approach for Hispanic women diagnosed with breast abnormalities. 
Cancer Epidemiology Biomarkers \& Prevention. 2012; 21(10):1639-1644. DOI: 10.1158/1055-9965.epi-12-0538

16. Elkin EB, Shapiro E, Snow JG, Zauber AG, Krauskopf MS. The economic impact of a patient navigator program to increase screening colonoscopy. Cancer. 2012; 118(23):5982-5988. DOI: 10.1002/cncr.27595 [PubMed: 22605672]

17. Ell K, Katon W, Lee PJ, Kapetanovic S, Guterman J, Xie B, Chou CP. Depressive symptom deterioration among predominantly Hispanic diabetes patients in safety net care. Psychosomatics. 2012; 53(4):347-355. [PubMed: 22458987]

18. Ell K, Padgett D, Vourlekis B, Nissly J, Pineda D, Sarabia O, Lee PJ. Abnormal mammogram follow-up - A pilot study in women with low income. Cancer practice. 2002; 10(3):130-138. DOI: 10.1046/j.1523-5394.2002.103009.x [PubMed: 11972567]

19. Ell K, Vourlekis B, Lee PJ, Xie B. Patient navigation and case management following an abnormal mammogram: A randomized clinical trial. Preventive Medicine. 2007; 44(1):26-33. DOI: 10.1016/ j.ypmed.2006.08.001 [PubMed: 16962652]

20. Ell K, Vourlekis B, Muderspach L, Nissly J, Padgett D, Pineda D, Lee PJ. Abnormal cervical screen follow-up among low-income Latinas: Project SAFe. Journal of Womens Health \& GenderBased Medicine. 2002; 11(7):639-651. DOI: 10.1089/152460902760360586

21. Ell K, Vourlekis B, Xie B, Nedjat-Haiem FR, Lee PJ, Muderspach L, Palinkas LA. Cancer treatment adherence among low-income women with breast or gynecologic cancer. Cancer. 2009; 115(19):4606-4615. DOI: 10.1002/cncr.24500 [PubMed: 19551881]

22. Fang CY, Ma GX, Tan Y, Chi NJ. A multifaceted intervention to increase cervical cancer screening among underserved Korean women. Cancer Epidemiology Biomarkers \& Prevention. 2007; 16(6): 1298-1302. DOI: 10.1158/1055-9965.epi-07-0091

23. Ferrante JM, Chen PH, Kim S. The effect of patient navigation on time to diagnosis, anxiety, and satisfaction in urban minority women with abnormal mammograms: A randomized controlled trial. Journal of Urban Health-Bulletin of the New York Academy of Medicine. 2008; 85(1):114-124. DOI: 10.1007/s11524-007-9228-9 [PubMed: 17906931]

24. Fiscella K, Whitley E, Hendren S, Raich P, Humiston S, Winters P, Epstein R. Patient navigation for breast and colorectal cancer treatment: A randomized trial. Cancer Epidemiology Biomarkers \& Prevention. 2012; 21(10):1673-1681. DOI: 10.1158/1055-9965.epi-12-0506

25. Freeman HP, Muth BJ, Kerner JF. Expanding access to cancer screening and clinical follow-up among the medically underserved. Cancer practice. 1995; 3(1):19-30. [PubMed: 7704057]

26. Gabram SGA, Lund MJB, Gardner J, Hatchett N, Bumpers HL, Okoli J, Brawley OW. Effects of an outreach and internal navigation program on breast cancer diagnosis in an urban cancer center with a large African-American population. Cancer. 2008; 113(3):602-607. DOI: 10.1002/cncr. 23568 [PubMed: 18613035]

27. Guadagnolo BA, Boylan A, Sargent M, Koop D, Brunette D, Kanekar S, Petereit DG. Patient navigation for American Indians undergoing cancer treatment utilization and impact on care delivery in a regional healthcare center. Cancer. 2011; 117(12):2754-2761. DOI: 10.1002/cncr. 25823 [PubMed: 21656754]

28. Haideri NA, Moormeier JA. Impact of patient navigation from diagnosis to treatment in an urban safety net breast cancer population. Journal of Cancer. 2011; 2:467-473. DOI: 10.7150/jca.2.467 [PubMed: 21915191]

29. Han HR, Lee H, Kim MT, Kim KB. Tailored lay health worker intervention improves breast cancer screening outcomes in non-adherent Korean-American women. Health Education Research. 2009; 24(2):318-329. DOI: 10.1093/her/cyn021 [PubMed: 18463411]

30. Hilgeman MM, Mahaney-Price AF, Stanton MP, McNeal SF, Pettey KM, Tabb KD, Alabama Veterans Rural Health Initiative Steering Committee. Alabama Veterans Rural Health Initiative: A pilot study of enhanced community outreach in rural areas. Journal of Rural Health. 2014; 30(2): 153-163. DOI: 10.1111/jrh.12054 [PubMed: 24330220]

31. Hoffman HJ, LaVerda NL, Young HA, Levine PH, Alexander LM, Brem R, Patierno SR. Patient navigation significantly reduces delays in breast cancer diagnosis in the District of Columbia. Cancer Epidemiology Biomarkers \& Prevention. 2012; 21(10):1655-1663. DOI: 10.1158/1055-9965.epi-12-0479 
32. Honeycutt S, Green R, Ballard D, Hermstad A, Brueder A, Haardorfer R, Arriola KJ. Evaluation of a patient navigation program to promote colorectal cancer screening in rural Georgia, USA. Cancer. 2013; 119(16):3059-3066. DOI: 10.1002/cncr.28033 [PubMed: 23719894]

33. Jandorf L, Braschi C, Ernstoff E, Wong CR, Thelemaque L, Winkel G, Itzkowitz SH. Culturally targeted patient navigation for increasing African Americans' adherence to screening colonoscopy: A randomized clinical trial. Cancer Epidemiology Biomarkers \& Prevention. 2013; 22(9):15771587. DOI: 10.1158/1055-9965.epi-12-1275

34. Jandorf L, Cooperman JL, Stossel LM, Itzkowitz S, Thompson HS, Villagra C, Redd W. Implementation of culturally targeted patient navigation system for screening colonoscopy in a direct referral system. Health Education Research. 2013; 28(5):803-815. DOI: 10.1093/her/cyt003 [PubMed: 23393099]

35. Jandorf L, Gutierrez Y, Lopez J, Christie J, Itzkowitz SH. Use of a patient navigator to increase colorectal cancer screening in an urban neighborhood health clinic. Journal of Urban HealthBulletin of the New York Academy of Medicine. 2005; 82(2):216-224. DOI: 10.1093/jurban/ jti046 [PubMed: 15888638]

36. Jandorf L, Stossel LM, Cooperman JL, Zivin JG, Ladabaum U, Hall D, Itzkowitz SH. Cost analysis of a patient navigation system to increase screening colonoscopy adherence among urban minorities. Cancer. 2013; 119(3):612-620. DOI: 10.1002/cncr.27759 [PubMed: 22833205]

37. Koh C, Nelson JM, Cook PF. Evaluation of a patient navigation program. Clinical Journal of Oncology Nursing. 2011; 15(1):41-48. DOI: 10.1188/11.CJON.41-48 [PubMed: 21278040]

38. Lairson DR, DiCarlo M, Deshmuk AA, Fagan HB, Sifri R, Katurakes N, Myers RE. Costeffectiveness of a standard intervention versus a navigated intervention on colorectal cancer screening use in primary care. Cancer. 2014; 120(7):1042-1049. DOI: 10.1002/cncr.28535 [PubMed: 24435411]

39. Lasser KE, Murillo J, Lisboa S, Casimir AN, Valley-Shah L, Emmons KM, Ayanian JZ. Colorectal cancer screening among ethnically diverse, low-income patients: A randomized controlled trial. Archives of Internal Medicine. 2011; 171(10):906-912. [PubMed: 21606094]

40. Lasser KE, Murillo J, Medlin E, Lisboa S, Valley-Shah L, Fletcher RH, Ayanian JZ. A multilevel intervention to promote colorectal cancer screening among community health center patients: results of a pilot study. Bmc Family Practice. 2009; 10:7.doi: 10.1186/1471-2296-10-37 [PubMed: 19159478]

41. Lebwohl B, Neugut AI, Stavsky E, Villegas S, Meli C, Rodriguez O, Rosenberg R. Effect of a patient navigator program on the volume and quality of colonoscopy. Journal of Clinical Gastroenterology. 2011; 45(5):E47-E53. DOI: 10.1097/MCG.0b013e3181f595c3 [PubMed: 21030874]

42. Lee JH, Fulp W, Wells K, Meade C, Calcano E, Roetzheim R. Effect of patient navigation on time to diagnostic resolution among patients with colorectal cancer-related abnormalities. Journal of Cancer Education. 2014; 29(1):144-150. DOI: 10.1007/s13187-013-0561-2 [PubMed: 24113902]

43. Lee JH, Fulp W, Wells KJ, Meade CD, Calcano E, Roetzheim R. Patient navigation and time to diagnostic resolution: Results for a cluster randomized trial evaluating the efficacy of patient navigation among patients with breast cancer screening abnormalities, Tampa, FL. Plos One. 2013; 8(9):8.doi: 10.1371/journal.pone.0074542

44. Leone LA, Reuland DS, Lewis CL, Ingle M, Erman B, Summers TJ, Pignone MP. Reach, usage, and effectiveness of a Medicaid patient navigator intervention to increase colorectal cancer screening, Cape Fear, North Carolina, 2011. Preventing Chronic Disease. 2013; 10:9.doi: 10.5888/ pcd10.120221

45. Ma GX, Shive S, Tan Y, Gao WZ, Rhee J, Park M, Toubbeh JI. Community-based colorectal cancer intervention in underserved Korean Americans. Cancer Epidemiology. 2009; 33(5):381386. DOI: 10.1016/j.canep.2009.10.001 [PubMed: 19914880]

46. Markossian TW, Darnell JS, Calhoun EA. Follow-up and timeliness after an abnormal cancer screening among underserved, urban women in a patient navigation program. Cancer Epidemiology Biomarkers \& Prevention. 2012; 21(10):1691-1700. DOI: 10.1158/1055-9965.epi-12-0535

47. Nash D, Azeez S, Vlahov D, Schori M. Evaluation of an intervention to increase screening colonoscopy in an urban public hospital setting. Journal of Urban Health-Bulletin of the New York 
Academy of Medicine. 2006; 83(2):231-243. DOI: 10.1007/s11524-006-9029-6 [PubMed: 16736372]

48. Nguyen TT, McPhee SJ, Bui-Tong N, Luong TN, Ha-Iaconis T, Nguyen T, Lam H. Communitybased participatory research increases cervical cancer screening among Vietnamese-Americans. Journal of Health Care for the Poor and Underserved. 2006; 17(2):31-54. DOI: 10.1353/hpu. 2006.0078 [PubMed: 16809874]

49. Oluwole SF, Ali AO, Adu A, Blane BP, Barlow B, Oropeza R, Freeman HP. Impact of a cancer screening program on breast cancer stage at diagnosis in a medically underserved urban community. Journal of the American College of Surgeons. 2003; 196(2):180-188. DOI: 10.1016/ s1072-7515(02)01765-9 [PubMed: 12595043]

50. Paskett ED, Katz ML, Post DM, Pennell ML, Young GS, Seiber EE, Ohio Patient Nav Res P. The Ohio Patient Navigation Research Program: Does the American Cancer Society patient navigation model improve time to resolution in patients with abnormal screening tests? Cancer Epidemiology Biomarkers \& Prevention. 2012; 21(10):1620-1628. DOI: 10.1158/1055-9965.epi-12-0523

51. Percac-Lima S, Ashburner JM, Bond B, Oo SA, Atlas SJ. Decreasing disparities in breast cancer screening in refugee women using culturally tailored patient navigation. Journal of General Internal Medicine. 2013; 28(11):1463-1468. DOI: 10.1007/s11606-013-2491-4 [PubMed: 23686510]

52. Percac-Lima S, Benner CS, Lui R, Aldrich LS, Oo SA, Regan N, Chabner BA. The impact of a culturally tailored patient navigator program on cervical cancer prevention in Latina women. Journal of Womens Health. 2013; 22(5):426-431. DOI: 10.1089/jwh.2012.3900

53. Percac-Lima S, Grant RW, Green AR, Ashburner JM, Gamba G, Oo S, Atlas SJ. A culturally tailored navigator program for colorectal cancer screening in a community health center: A randomized, controlled trial. Journal of General Internal Medicine. 2009; 24(2):211-217. DOI: 10.1007/s11606-008-0864-x [PubMed: 19067085]

54. Percac-Lima S, Lopez L, Ashburner JM, Green AR, Atlas SJ. The longitudinal impact of patient navigation on equity in colorectal cancer screening in a large primary care network. Cancer. 2014; 120(13):2025-2031. DOI: 10.1002/cncr.28682 [PubMed: 24691564]

55. Percac-Lima S, Milosavljevic B, Oo SA, Marable D, Bond B. Patient navigation to improve breast cancer screening in Bosnian refugees and immigrants. Journal of Immigrant and Minority Health. 2012; 14(4):727-730. DOI: 10.1007/s10903-011-9539-5 [PubMed: 22009215]

56. Petereit DG, Molloy K, Reiner ML, Helbig P, Cina K, Miner R, Roberts CR. Establishing a patient navigator program to reduce cancer disparities in the American Indian communities of Western South Dakota: Initial observations and results. Cancer Control: Journal of the Moffitt Cancer Center. 2008; 15(3):254-259. [PubMed: 18596678]

57. Phillips CE, Rothstein JD, Beaver K, Sherman BJ, Freund KM, Battaglia TA. Patient navigation to increase mammography screening among inner city women. Journal of General Internal Medicine. 2011; 26(2):123-129. DOI: 10.1007/s11606-010-1527-2 [PubMed: 20931294]

58. Rahm AK, Sukhanova A, Ellis J, Mouchawar J. Increasing utilization of cancer genetic counseling services using a patient navigator model. Journal of genetic counseling. 2007; 16(2):171-177. DOI: 10.1007/s10897-006-9051-6 [PubMed: 17277995]

59. Raich PC, Whitley EM, Thorland W, Valverde P, Fairclough D. Patient navigation improves cancer diagnostic resolution: An individually randomized clinical trial in an underserved population. Cancer Epidemiology Biomarkers \& Prevention. 2012; 21(10):1629-1638. DOI: 10.1158/1055-9965.epi-12-0513

60. Ramirez A, Perez-Stable E, Penedo F, Talavera G, Carrillo JE, Fernandez M, Gallion K. Reducing time-to-treatment in underserved Latinas with breast cancer. Cancer. 2014; 120(5):752-760. [PubMed: 24222098]

61. Ramirez AG, Perez-Stable EJ, Penedo FJ, Talavera GA, Carrillo JE, Fernandez ME, Gallion K. Navigating Latinas with breast screen abnormalities to diagnosis. Cancer. 2013; 119(7):12981305. DOI: 10.1002/cncr.27912 [PubMed: 23233265]

62. Ravenell J, Thompson H, Cole H, Plumhoff J, Cobb G, Afolabi L, Ogedegbe G. A novel community-based study to address disparities in hypertension and colorectal cancer: A study protocol for a randomized control trial. Trials. 2013; 14:13.doi: 10.1186/1745-6215-14-287 [PubMed: 23305152] 
63. Redwood D, Provost E, Perdue D, Haverkamp D, Espey D. The last frontier: Innovative efforts to reduce colorectal cancer disparities among the remote Alaska Native population. Gastrointestinal Endoscopy. 2012; 75(3):474-480. DOI: 10.1016/j.gie.2011.12.031 [PubMed: 22341095]

64. Schwaderer KA, Proctor JW, Martz EF, Slack RJ, Ricci E. Evaluation of patient navigation in a community radiation oncology center involved in disparities studies: A time-to-completion-oftreatment study. Journal of Oncology Practice. 2008; 4(5):220-224. DOI: 10.1200/JOP.0852001 [PubMed: 19169417]

65. Scott LB, Gravely S, Sexton TR, Brzostek S, Brown DL. Effect of patient navigation on enrollment in cardiac rehabilitation. JAMA internal medicine. 2013; 173(3):244-246. DOI: 10.1001/2013.jamainternmed.1042 [PubMed: 23247823]

66. Scott LB, Gravely S, Sexton TR, Brzostek S, Brown DL. Examining the effect of a patient navigation intervention on outpatient cardiac rehabilitation awareness and enrollment. Journal of Cardiopulmonary Rehabilitation and Prevention. 2013; 33(5):281-291. DOI: 10.1097/HCR. 0b013e3182972dd6 [PubMed: 23823904]

67. Shlay JC, Barber B, Mickiewicz T, Maravi M, Drisko J, Estacio R, Urbina C. Reducing cardiovascular disease risk using patient navigators, Denver, Colorado, 2007-2009. Preventing Chronic Disease. 2011; 8(6):1-11.

68. Simon MA, Nonzee NJ, McKoy JM, Liu DC, Luu TH, Byer P, Rademaker AW. Navigating veterans with an abnormal prostate cancer screening test: A quasi-experimental study. BMC Health Services Research. 2013; 13:8.doi: 10.1186/1472-6963-13-314 [PubMed: 23289629]

69. Tingen MS, Weinrich SP, Heydt DD, Boyd MD, Weinrich MC. Perceived benefits: A predictor of participation in prostate cancer screening. Cancer Nursing. 1998; 21(5):349-357. DOI: 10.1097/00002820-199810000-00006 [PubMed: 9775485]

70. Walker EA, Stevens KA, Persaud S. Promoting diabetes self-management among African Americans: An educational intervention. Journal of Health Care for the Poor and Underserved. 2010; 21(3):169-186. [PubMed: 20675953]

71. Wang XJ, Fang C, Tan Y, Liu A, Ma GX. Evidence-based intervention to reduce access barriers to cervical cancer screening among underserved Chinese American women. Journal of Womens Health. 2010; 19(3):463-469. DOI: 10.1089/jwh.2009.1422

72. Warren-Mears V, Dankovchik J, Patil M, Fu RW. Impact of patient navigation on cancer diagnostic resolution among Northwest tribal communities. Journal of Cancer Education. 2013; 28(1):109_ 118. DOI: 10.1007/s13187-012-0436-y [PubMed: 23242563]

73. Weber JJ, Mascarenhas DC, Bellin LS, Raab RE, Wong JH. Patient navigation and the quality of breast cancer care: An analysis of the breast cancer care quality indicators. Annals of Surgical Oncology. 2012; 19(10):3251-3256. DOI: 10.1245/s10434-012-2527-8 [PubMed: 22814513]

74. Weinrich SP, Boyd MD, Weinrich M, Greene F, Reynolds WA Jr. Metlin C. Increasing prostate cancer screening in African American men with peer-29 educator and client-navigator interventions. Journal of Cancer Education. 1998; 13(4):213-219. [PubMed: 9883780]

75. Wells KJ, Lee JH, R CE, D MC, Rivera M, Fulp WJ, Roetzheim RG. A cluster randomized trial evaluating the efficacy of patient navigation in improving quality of diagnostic care for patients with breast or colorectal cancer abnormalities. Cancer Epidemiology, Biomarkers \& Prevention. 2012; 21(10):1664-1672. DOI: 10.1158/1055-9965.EPI-12-0448

\section{Appendix 2: Data Abstraction Template}

\begin{tabular}{|l|}
\hline Mention of training \\
\hline Training mentioned and described \\
\hline Training mentioned, but not described \\
\hline Training not mentioned/described \\
\hline Duration/frequency of training \\
\hline Massed \\
\hline
\end{tabular}




\begin{tabular}{|l|} 
Distributed \\
\hline Massed/distributed unknown \\
\hline Total duration (mentioned) \\
\hline Total duration (write in description) \\
\hline Duration/frequency: ANY TYPE (mentioned)
\end{tabular}

Duration/frequency: ANY TYPE (mentioned)

Training location

Local

National

Specific location (mentioned)

Specific location (write in description)

Training location: ANY TYPE (mentioned)

Training format

Conference

Class/course

Seminar

Program

Session(s)

Symposium

Educational update

Continuing education

Webinar

Via telephone

Workshop

Staff meetings

Other

Training format: ANY TYPE (mentioned)

Occupation of trainer

Self-administered

Medical worker/team

Research investigator/team

Clinical psychologist

Social worker

Other

Occupation of trainer: ANY TYPE (mentioned)

Content of training

Navigation (generally)

Education about the intervention

Cultural competency

Theory-based techniques

General communication skills 
Information about cancer or other health/disease topics

General adherence strategies

Confidentiality/Privacy practices training

Maintaining professional boundaries

Computer skills training

Research training

Assessment training

General coordination of care

Patient-provider issues

Addressing psychosocial needs

Obtaining insurance

Structural/logistical issues

Financial issues

Obtaining travel/lodging

Safety concerns

Barriers

Other

Content of training: ANY TYPE (mentioned)

Learning strategy

Passive

Hear (ex. lecture)

See (ex. manual, handouts)

See and Hear NOT ON SITE (ex. audiovisual, movie, demonstration)

See and Hear ON SITE (ex. observation)

Passive learning strategy: ANY TYPE (mentioned)

Active

Say (ex. group discussion)

Do NOT ON SITE (ex. role play, interactive exercises)

Do ON SITE (ex. on-the-job training)

Active learning strategy: ANY TYPE (mentioned)

Learning strategy: ANY TYPE (mentioned)

Other

Supervision/Support

Navigator-to-navigator collaboration

Navigator involvement in training content

Paid

Manualized interventions

Specific group providing training (mentioned)

Specific group providing training (write-in description)

Health Promot Pract. Author manuscript; available in PMC 2017 May 01. 


\section{References}

American College of Surgeons Commision on Cancer. Cancer Program Standards 2012: Ensuring patient-centered care. 2012. from https://http://www.facs.org/ /media/files/qualityprograms/ cancer/coc/programstandards2012.ashx

Braun KL, Allison A, Tsark JU. Using community-based research methods to design cancer patient navigation training. Progress in community health partnerships: research, education, and action. 2008; 2(4):329-340. DOI: 10.1353/cpr.0.0037

Braun KL, Kagaiva-Singer M, Holden AEC, Burhansstipanov L, Tran JH, Seals BF, Ramirez AG. Cancer patient navigator tasks across the cancer care continuum. Journal of Health Care for the Poor and Underserved. 2012; 23(1):398-413. [PubMed: 22423178]

Bryant DC, Williamson D, Cartmell K, Jefferson M. A lay patient navigation training curriculum targeting disparities in cancer clinical trials. Journal of National Black Nurses' Association: JNBNA. 2011; 22(2):68-75. [PubMed: 23061182]

Byers T. Assessing the value of patient navigation for completing cancer screening. Cancer Epidemiology Biomarkers \& Prevention. 2012; 21(10):1618-1619. DOI: 10.1158/1055-9965.epi-12-0964

Calhoun EA, Whitley EM, Esparza A, Ness E, Greene A, Garcia R, Valverde PA. A national patient navigator training program. Health promotion practice. 2010; 11(2):205-215. DOI: 10.1177/1524839908323521 [PubMed: 19116415]

Clark JA, Parker VA, Battaglia TA, Freund KM. Patterns of task and network actions performed by navigators to facilitate cancer care. Health Care Management Review. 2014; 39(2):90-101. DOI: 10.1097/HMR.0b013e31828da41e [PubMed: 23478753]

Davidson KW, Goldstein M, Kaplan RM, Kaufmann PG, Knatterud GL, Orleans CT, Whitlock EP. Evidence-based behavioral medicine: What is it and how do we achieve it? Annals of Behavioral Medicine. 2003; 26(3):161-171. DOI: 10.1207/s15324796abm2603_01 [PubMed: 14644692]

DeGroff A, Coa K, Morrissey KG, Rohan E, Slotman B. Key considerations in designing a patient navigation program for colorectal cancer screening. Health promotion practice. 2014; 15(4):483495. DOI: 10.1177/1524839913513587 [PubMed: 24357862]

Dohan D, Schrag D. Using navigators to improve care of underserved patients - Current practices and approaches. Cancer. 2005; 104(4):848-855. DOI: 10.1002/cncr.21214 [PubMed: 16010658]

Freeman HP. The Origin, evolution, and principles of patient navigation. Cancer Epidemiology Biomarkers \& Prevention. 2012; 21(10):1614-1617. DOI: 10.1158/1055-9965.epi-12-0982

Freeman HP, Muth BJ, Kerner JF. Expanding access to cancer screening and clinical follow-up among the medically underserved. Cancer practice. 1995; 3(1):19-30. [PubMed: 7704057]

Ghebre RG, Jones LA, Wenzel JA, Martin MY, Durant RW, Ford JG. State-of-the-science of patient navigation as a strategy for enhancing minority clinical trial accrual. Cancer. 2014; 120:11221130. DOI: $10.1002 /$ cncr.28570 [PubMed: 24643650]

Hopkins J, Mumber MP. Patient navigation through the cancer care continuum: An overview. Journal of Oncology Practice. 2009; 5(4):150-152. DOI: 10.1200/jop.0943501 [PubMed: 20856626]

Klimmek RK, Noyes E, Edington-Saunders K, Logue C, Jones R, Wenzel J. Training of community health workers to deliver cancer patient navigation to rural African American seniors. Progress in Community Health Partnerships-Research Education and Action. 2012; 6(2):167-174.

Merriam, SB.; Caffarella, RS.; Baumgartner, LM. Learning in adulthood: A comprehensive guide. 3 ed. Jossey-Bass; San Francisco: 2007.

National Accreditation Program for Breast Centers. NAPBC Standards Manual 2014 Edition. 2014. from https://http://www.facs.org/ /media/files/qualityprograms/napbc/2014 napbc standards manual.ashx

Noe, RA. Employee training and development. 3 ed. McGraw-Hill/Irwin; New York: 2005.

Oncology Nursing Society, Association of Oncology Social Work; National Association of Social Workers. Oncology Nursing Society, the Association of Oncology Social Work, and the National Association of Social Workers joint position on the role of oncology nursing and oncology social work in patient navigation. Oncology nursing forum. 2010; 37(3):251-252. [PubMed: 20439209] 
Ostroff JS, Shuk E, Krebs P, Lu WH, Burkhalter J, Cortez-Weir J, Lubetkin EI. Qualitative evaluation of a new tobacco cessation training curriculum for patient navigators. Journal of Cancer Education. 2011; 26(3):427-435. DOI: 10.1007/s13187-011-0229-8 [PubMed: 21553331]

Paskett ED, Harrop JP, Wells KJ. Patient navigation: An update on the state of the science. Ca: A Cancer Journal for Clinicians. 2011; 61(4):237-249. DOI: 10.3322/caac.20111 [PubMed: 21659419]

Patient Navigator Outreach and Chronic Disease Prevention Act. U.S.C. §. 2005; 42:1812.

Patient Protection and Affordable Care Act. U.S.C. §. 2010; 42:3510.

Schapira L, Schutt R. Training community health workers about cancer clinical trials. Journal of Immigrant and Minority Health. 2011; 13(5):891-898. DOI: 10.1007/s10903-010-9432-7 [PubMed: 21181445]

Shelton RC, Thompson HS, Jandorf L, Varela A, Oliveri B, Villagra C, Redd WH. Training experiences of lay and professional patient navigators for colorectal cancer screening. Journal of Cancer Education. 2011; 26(2):277-284. DOI: 10.1007/s13187-010-0185-8 [PubMed: 21287311]

Thompson, D. A brief history of research and theory on adult learning and cognition. In: Smith, MC.; DeFrates-Densch, N., editors. Handbook of Research on Adult Learning and Development. Routledge; New York, NY: 2009. p. 479

Wells KJ, Battaglia TA, Dudley DJ, Garcia R, Greene A, Calhoun E, Raich PC. Patient navigation: State of the art or is it science? Cancer. 2008; 113(8):1999-2010. DOI: 10.1002/cncr.23815 [PubMed: 18780320] 


\section{Table 1}

\section{Characteristics of 75 studies included in review}

\begin{tabular}{|l|r|c|}
\hline Study Characteristics & $\boldsymbol{n}$ & $\boldsymbol{\%}$ \\
\hline Model of navigation & & \\
\hline Lay only & 23 & $31 \%$ \\
\hline Professional only & 12 & $16 \%$ \\
\hline Multidisciplinary team & 11 & $15 \%$ \\
\hline Unclassifiable & 29 & $39 \%$ \\
\hline Culturally competent & 32 & $43 \%$ \\
\hline Disease type & & \\
\hline Breast cancer & 32 & $43 \%$ \\
\hline Colorectal cancer & 26 & $35 \%$ \\
\hline Cervical cancer & 10 & $13 \%$ \\
\hline Prostate cancer & 6 & $8 \%$ \\
\hline Cancer (Other type/Type not specified) & 8 & $11 \%$ \\
\hline Cardiovascular disease & 3 & $4 \%$ \\
\hline Diabetes & 3 & $4 \%$ \\
\hline Human immunodeficiency virus & 1 & $1 \%$ \\
\hline Other & 1 & $1 \%$ \\
\hline Stage of disease continuum & & \\
\hline Screening & 32 & $43 \%$ \\
\hline Diagnosis & 26 & $35 \%$ \\
\hline Treatment & 20 & $27 \%$ \\
\hline Survivorship/Rehabilitation & 5 & $7 \%$ \\
\hline Stage at Diagnosis & 3 & $4 \%$ \\
\hline Prevention & 2 & $3 \%$ \\
\hline Survival & 1 & $1 \%$ \\
\hline Other & $3 \%$ \\
\hline & & \\
\hline & & \\
\hline & & \\
\hline
\end{tabular}

Percentage out of the 75 studies included in review 
Table 2

Training domains described in studies mentioning training

\begin{tabular}{|l|r|c|}
\hline Training Domain & $\boldsymbol{n}$ & $\boldsymbol{\%}^{*}$ \\
\hline Type of training domain & & \\
\hline Content & 47 & $80 \%$ \\
\hline Duration & 31 & $53 \%$ \\
\hline Occupation of trainer & 30 & $51 \%$ \\
\hline Format & 27 & $46 \%$ \\
\hline Location & 16 & $27 \%$ \\
\hline Learning strategy & 16 & $27 \%$ \\
\hline Number of training domains described & & \\
\hline 6 & 0 & $0 \%$ \\
\hline 5 & 11 & $19 \%$ \\
\hline 4 & 13 & $22 \%$ \\
\hline 3 & 7 & $12 \%$ \\
\hline 2 & 15 & $25 \%$ \\
\hline 1 & 9 & $15 \%$ \\
\hline 0 & 4 & $7 \%$ \\
\hline
\end{tabular}

Percentage out of the 59 studies mentioning training 


\section{Table 3}

\section{Description of training content by type}

\begin{tabular}{|l|r|r|}
\hline Type of Training Content & $\boldsymbol{n}$ & $\boldsymbol{\%}^{*}$ \\
\hline Topics related to patient care & 33 & $56 \%$ \\
\hline Coordination of care & 26 & $44 \%$ \\
\hline Barriers to care & 14 & $24 \%$ \\
\hline Psychosocial needs & 10 & $17 \%$ \\
\hline Patient-provider issues & 4 & $7 \%$ \\
\hline Adherence strategies & 3 & $5 \%$ \\
\hline Developing navigator skills & 28 & $47 \%$ \\
\hline Theory-based techniques & 17 & $29 \%$ \\
\hline Cultural competency & 14 & $24 \%$ \\
\hline Assessment & 8 & $14 \%$ \\
\hline Communication & 7 & $12 \%$ \\
\hline Confidentiality/privacy & 4 & $7 \%$ \\
\hline Maintaining professional boundaries & 3 & $5 \%$ \\
\hline Computer skills & 1 & $2 \%$ \\
\hline Cancer and health education & 23 & $39 \%$ \\
\hline Other & 21 & $36 \%$ \\
\hline
\end{tabular}

Percentage out of the 59 studies mentioning training 